\title{
Measuring Efficacy of an Online Reading Literacy Program in English - A New Conceptual Framework
}

\author{
Sheeba Jojo ${ }^{a}$, Varughese Kizhakkacharuvil John ${ }^{b}$ \\ a sheeba.jojo@gmail.com \\ ${ }^{\text {a }}$ PhDTEM Student, Assumption University, Thailand \\ ${ }^{\mathrm{b}}$ Assoc. Professor, Assumption University, Thailand,
}

\begin{abstract}
The objective of this study is to develop a conceptual framework for testing the efficacy of an online reading program, namely, 'Literacy Pro' which was developed by Scholastic Corporation in the US to improve the English reading and comprehension skill of students. The conceptual framework that is developed will also measure the impact of students' performance in international English proficiency exams, such as PISA, PIRLS, TIMSS, and ASSET after they have participated in the online reading literacy program. It is the accurate and timely identification of the students 'at-risk' in reading difficulties so that additional instructions or interventions can be provided. From the measurement perspective, effective screening tools demonstrated high levels of sensitivity in identifying those students who will actually encounter reading difficulties, as well as high levels of specificity in the accurate identification of those students who are not likely to demonstrate reading difficulties. A research instrument is adapted to explore the reading strategies used by the students and recommended by the teachers. Effective reading strategy involves self-directed control of the learning process inside and outside the classroom.
\end{abstract}

Published by IJRP.ORG. Selection and/or peer-review under responsibility of International Journal of Research Publications (IJRP.ORG)

Keywords: Literacy Pro; Online English Reading; Reading Comprehension; Reading Skills; Reading Strategies; Sensitivity; Specificity

\section{Introduction}

The purpose of this study is to develop a conceptual framework based on related literature to test the efficacy of an online reading program called 'Literacy Pro' for improving students' reading skill and comprehension. Furthermore, the study aims to focus on the effectiveness of facilitating personalized reading through an online platform aimed at improving reading literacy of individual students based on their lexile levels generated through online reading assessments on 'Literacy Pro'. Consequently, the study also aims to explore the relationship between the impact of the online reading program and student performance in International benchmark exams like PISA, PIRLS, TIMSS \& ASSET in English. The 
conceptual framework developed through a literature review is significant and intended to help curriculum designers, policy makers, school students as well as school teachers. This will in turn help all stake-holders to analyze and evaluate the potential of online reading programs in enabling and improving the standards of reading literacy. Subsequently, the data collected and analyzed through further research may be used as reference to design and develop cheaper, effective online reading literacy courses/tools for schools that enhance the reading skills of students.

\section{Literature Review}

\subsection{Reading Literacy}

Reading Literacy is a skill, which is the foundation of almost all processes of learning and is necessary for students not only to acquire languages and study literature, but also to learn other subjects (Geske \& Ozola, 2009). Mullis, Kennedy, Martin, and Sainsbury (2004) have defined 'Reading Literacy' as "the ability to understand and use those written language forms required by society and/or valued by the individuals" (p.3). It has been surmised in a study by Lea and Jones (2011) that, reading has an integral role with respect to the choices that students make with the textual resources available to them. This idea is further reinforced by Calhoon (2005) in his study; "Reading ability is a fundamental skill on which academic success, secure employment and personal autonomy depend" (p.424). Reutzel and Cooter (2004) too contend that the primary goal of any comprehensive reading program ought to be to transform students into independent and fluent readers who continue to fine-tune their literacy skills throughout their schooling. Research by Kern (1989) says that reading in any language is cognitively demanding and reading in a second language tends to put greater stress on the reader. It has been surmised that students who are exposed to a variety of reading texts are seen to develop critical reading skills; eventually, they also develop "independent thinking and skills in analysis and judgement" (p. 42).

In a study, Vasquez (2009) asserts that, "an individual's lack of reading skills produces functional deficits in response to environmental demands and produces long term limitations in future, more complex and technical environments" (p.1). According to L. E. Shanahan (2006), academic success to a large extent depends on a student's robust foundation of basic literacy skills. The positive impact of good reading and literacy skills on learning as well as the adverse effect of lack of these skills on academic output has also been established in a research by Fisher (2012). Elley (1992) claims that educators across the world have been divided in their opinion about how best to teach children to read. There have been many challenges to teaching reading. For a long time, schools depended on graded readers and a wide variety of children's literature to improve reading skills.

As cited by Richmond (1980), during the early years, reading literacy was taught through an oral approach; mimicry, memorization and other audio-visual technics piqued the interest of the young learners. Many researchers have alluded to the different stages in the teaching and learning of the reading process: at the preschool or kindergarten level, the focus is on reading readiness programs; reading skills begin to develop through strategies for decoding and comprehension in the primary; wide reading that is the result of recreational reading is developed through the middle school and high school years (Smith, 2005). It is expected that by then students would have developed their reading both in terms of volume and difficulty leading to a level of comfort that supports their endeavours for living and life-long learning.

The work of Stewart-Dore (2013) posits that since the 1800 s, content-area reading has been a part of education, providing students with reading strategies that help in comprehending different types of content-area texts. This view is supported by T. Shanahan and Shanahan (2012), who advocate that content area skills have been given great importance as it has been observed that, students with low levels of reading proficiency who are easily distracted fail to comprehend all the details of what they are reading; 
they focus on finishing the reading task than on comprehending the text. They also found that if students are taught active reading strategies, they will be able to establish greater engagement with the text resulting in a greater understanding of the reading task, setting reading goals for themselves and even summarizing what they have read. Furthermore, Hynd-Shanahan (2013) mentions that, in an attempt to improve skills in reading comprehension, students must be provided with a 'toolbox' of strategies that aid reading irrespective of the nature of content. This idea is echoed in a study by White (2004), who states that some of these tools will assist students to achieve certain expectations of reading like the ability to differentiate between fact and opinion; identifying and analyzing evidence, assumptions and conclusions. However, later research also suggests that these strategies alone will not equip students for life long reading of discipline-specific texts and tasks they might encounter later (Collin, 2014).

\subsection{Strategies for effective reading}

The reading level of a reader depends a great deal on the strategies that one adopts for reading with respect to his own competency in reading in the second language (Cziko, 2006). Besides, researchers like Kern (1989) claim that fluency in reading is the result of substantial amount of practice over a long period of time. A study by Rashotte and Torgesen (1985) showed that readers' comprehension was better with respect to passages that had words known to them. Faulkner and Levy (1999) advocate the repeated reading of passages that share words was mandatory. Grabe (2009), and Zhang (2012) suggest that a reader constructs meaning by virtue of his linguistic knowledge. There is hard work involved in improving one's ability to read. Thus, Dagostino and Carifio (1994), emphasize the interplay of strategies in place to retain, organize and evaluate information that is being read.

Research states that there is a strong relationship between one's knowledge of vocabulary and his ability to read. Stanovich and Cunningham (1992) contend that good knowledge of vocabulary has a strong link to reading comprehension. Hart and Risley (2003) reinforce this idea in their study by stating that, vocabulary building endeavours in early childhood are significant indicators of performance through the schooling years. Zwaan and Rapp (2006) suggest that lexical as well grammatical items serve as cues in establishing coherence across areas of reading. Additionally, researchers like Graves and Watts-Taffe (2008) have suggested that "word consciousness" or "word awareness" might be an important factor in promoting vocabulary.

Graves and Watts-Taffe (2008) have listed four main features of a curriculum to teach vocabulary which they claim will contribute towards enhancing their vocabulary and ultimately their reading comprehension skills: teaching of individual words, encouraging extensive reading, teaching word-learning strategies and promoting word consciousness. Researchers claim that students can be trained with the use of appropriate instructions to use contextual clues to delineate meaning effectively (Fukkink \& de Glopper, 1998). Subsequently, some have quantified a threshold level of knowledge of vocabulary to categorize readers' ability to read (Zhang, 2012). Furthermore, reasonable and unassisted reading comprehension is measured on the basis of a reader's awareness of a certain percentage of words in a given text (Nation, 2006). Hence, one may agree with Grabe (2009) that reading plays a significant role in the acquisition of a second language and a fairly good grasp of vocabulary must be ensured.

\subsection{Assessment of reading comprehension}

To gain a clear understanding of whether readers understand what they read, research must rely on readers' ability to reconstruct meaning on assessment tasks post reading sessions (Wolf, 2011). Wolf further suggests that the difficulty to assess comprehension lies in the fact that the process by which readers create meaning from a printed text is quite elusive. According to Bernhardt (1983) the type of tasks used to assess comprehension may direct readers to adopt strategies for reading. For instance, a cloze exercise might not be ideal to measure comprehension as it fails to record actual reading skills. 


\subsection{Current trends - web-based / Online Reading Literacy Program}

Studies like the one conducted by Blanchard, McLain, and Bartshe (2004) state that, "the marriage of reading and technology works well" (p.8). Paradigms of student learning and instruction have been revolutionized by the advent of technology in the classroom (Iyer, 2003). Coiro (2012) defines online reading as varied reading activities that take place on the internet. According to Auer (2014), digital reading materials have become increasing popular in recent times with student appeal for mobile devices. The reading path provided by web-based programs is quite different from the traditional single channel; it is now a self-designed non-linear trajectory (Al-Shehri \& Gitsaki, 2010). A web-based reading program is the facility to provide specific content and a customized program that focuses on both instruction and assessment through real time reporting; it has the facility to provide instant feedback and remediation. According to Cole and Hilliard (2006) "a web-based instruction provides an active learning environment that epitomizes learning that is student-centered, interactive, exploratory, contextualized, intentional, reflective and collaborative" (p.365).

Reading on the web is a dynamic exercise as readers may be directed to multiple reading paths and may be offered many interesting choices of activities to enhance their reading experience through links and hyper-links (Schmar-Dobler, 2003). The visual and audio multimedia elements integrated into the text also add to the appeal of such programs. Park and Kim (2011) have also commented on the vivid experience provided by the multi-media elements in web-based reading programs. The richness of such resources provided online has been noted by Massey (2014). The interactive feature of web-based programs enables to stimulate and sustain motivation which is inherent to the learning process (Palmer, 2006). Research by Goodfellow and Lea (2005) also stresses on the role of web-based programs in enhancing motivation among learners. This view is also supported by Eilon and Kliachko (2004) who have recorded that technology driven learning environment sustains motivation of a learner by constantly challenging their thinking through tasks suitable to their skill level. A computer mediated environment keeps up the motivation level in learners. Thus, researchers like Harrison (2009) believe that technology provides a learning system that embeds reading strategies that enable learners to improve their reading literacy skills.

Sadik (2008) articulates that through online technology integration, learning becomes a more pleasurable experience as student learn within a social context as well are provided the opportunity to create knowledge as they go along. This idea has been well summarized by Jones (2001), when he says that acquisition of literacy skills is "a fluid process" one that takes places seamlessly in a social context where students are not passive learners, but instead active participants in the construction of knowledge. Hence, online reading literacy programs empower students as they take control of their own learning and makes them more accountable as well. This accountability also manifests as intrinsic motivation which fuels greater task involvement and eventually learning achievement (Chun-Min \& Thomas, 2007). Similar ideas are echoed in a study by Palmer (2006) who says that learning becomes meaningful when learners are actively involved in the process. Similarly, Perlman, Weston, and Gisel (2010) too have found that an increased sense of ownership and responsibility is observed among learners engaged in web-based learning. Lamb and Johnson (2010) also assert that student skills in a variety of curricula areas would show improvement through interactive learning environments provided on the web.

It has also been observed by many researchers that online reading literacy programs facilitate effective intervention for struggling readers in the form of personalized instruction (Englert, Manalo, \& Zhao, 2004). By virtue of their ability to provide high engagement levels, web-based programs are deemed an effective tool for providing additional reading practice to students identified as at risk of reading failure (Smith \& Throne, 2007). Besides, as mentioned by Littleton, Wood, and Chera (2006), online reading programs not only allow students the liberty to work at their own pace but also provide them with instant feedback. Fasting and Lyster (2005) too have found benefits for struggling readers on technology driven reading platforms. 


\subsection{Future of reading literacy}

It is only possible to change the culture of reading by affecting some significant changes to the factors that shape this culture. This entails a change from many of the traditional methods of reading to new technology driven strategies in reading; a change that might take its time to produce visible results (Cortazzi \& Jin, 2008). It is mandatory that curricular objectives that focus on reading literacy are instituted and teacher awareness about instructional strategies to raise reading literacy are stepped up (Hayes \& Schrier, 2000). The focus of web-based programs must focus on the five core areas of literacy learning: Phonemic awareness, phonics, fluency, vocabulary and comprehension (Eunice Kennedy Shriver National Institute of Child Health and Human Development, 2001).

In their research Biancarosa and Snow (2004) acknowledge that technology can certainly enhance traditional modes of instruction; however, a careful needs analysis is to be conducted to align student skill to the capabilities provided by technology applications. Researchers like Carney (2010) have also pointed out that web-based programs ought not to attempt to oust the teacher from her role, must rather enhance the teacher's capability in individualizing learning for a learner. Sherman, Kleiman, and Peterson (2004) too supports the above view that technology supplements the role of a teacher.

Little research gives insight into which conditions actually improve comprehension. Besides, we must also look into what factors make some students more effective independent readers than others. Besides, there's little evidence that points in the direction of a particular type of knowledge, vocabulary or grammar that predominantly has an influence on reading comprehension skills of L2 readers (Zhang, 2012). Researchers like Cole, J.M \& Hillard, V.R (2006), have documented the significant improvement in reading comprehension using web based instruction as against traditional methods of reading. Dehghanpour et al. (2015) support a similar view in their research that affirms a positive attitude shift towards web-based reading strategy instruction.As summarized by Lovell and Phillips (2009), there is much research that emphasizes the role of technology as bringing about disruption in the field of education; however, there is little research that points towards the effective programs to be used in an online environment. Also, there is little research on second language readers and their level of proficiency in response to online reading (Foasberg, 2014). Thus, there is a growing sense of disillusionment among educators regarding web-based learning as its role in literacy achievement for students remains questionable. Hence, there is a need for further research to ascertain the effectiveness of web-based reading literacy programs and their impact on student achievement.

\section{Methodology}

\subsection{Background of the study}

The schools in the United Arab Emirates (U.A.E) are the focus of the study. All schools in the U.A.E are expected to show progress and attainment with respect to student achievement as mandated by the U.A.E Vision 2021 National Agenda Parameters in Education (NAPE). One of the focus areas of NAPE is reading. According to Richmond (1980), reading Literacy programs are considered as crucial to survival both at the individual and national level, so is the case in the U.A.E too. U.A.E is working towards earning itself a position among the highest performing countries in PISA (Program for International Student Assessment) and among the highest performing countries in the world for TIMSS (Trends in International Mathematics and Science). In the context of the NAPE, student achievement in the schools in the U.A.E is measured by comparing their performance with that of students from the rest of the world in International benchmark examinations like PISA, and TIMSS. PIRLS (Progress in International Reading Literacy Study) is also administered among the students of grade IV to assess their reading skills. All these examinations test the skills and knowledge of the students at certain year levels. Students are 
expected to take these tests online, in examination conditions without any assistance from their teachers. Each year, greater emphasis is put on schools to achieve the scores assigned to them to raise the progress and attainment of every student in a class. This is indeed a great challenge and raising student levels in reading comprehension is definitely a prerequisite.

\subsection{Statement of Problem}

How can schools provide teaching with instructional tools to assess student potential and levels in learning, and institute effective processes to improve progress and attainment in international benchmark examinations such as PISA, PIRLS, TIMSS, and ASSET? This has come to be the standard for assessing individual student and school success to a large extent. Providing individual, one to one learning assistance to raise standards in reading comprehension, based on the learning needs of every child may be the ideal solution to raise students' achievement in terms of progress and attainment. However, this is not an easy solution and may not always be practical in a school set-up. As stated by researchers like Fishman, Ferguson, and Dasgupta (1968), the problem of literacy is most acute in multilingual societies. They recommended the need to include literacy techniques as an integral part of national education for the success of the nation.

Traditional reading literacy programs have focused on a drill and skill approach that was predominantly teacher centered. Hence, transferring of skills required to master the art of reading comprehension was not successfully achieved by students (Armstrong \& Newman, 2011; Grubb \& Gabriner, 2013). Many of the articles published on the topic of reading literacy feature frameworks for curriculum design but lack any data to support student success with such programs (Armstrong \& Newman, 2011).

The school ratings pronounced by the National body that audits schools in UAE, Knowledge and Human Development Authority (KHDA) will only go up in proportion to the progress and attainment of the students in International benchmark examinations. Therefore, it is imperative to introduce effective reading programs to raise reading comprehension among students. It is a challenge to track progress in reading among students through traditional methods that assess the knowledge of vocabulary and fluency in reading among other parameters. Hence, this study develops a model to measure and analyze the impact of an online reading literacy program called 'Literacy Pro'. It is believed that this program will subsequently have a positive impact on the progress and attainment of students.

\subsection{Research Objective}

The primary objective of this study is to develop a conceptual framework for the measurement of the efficacy of the online Reading application 'Literacy Pro' in improving the reading skill and reading comprehension of students studying at different grades at the School level in the UAE where the application has been currently in vogue.

\subsection{Reading Skill Intervention Program- 'Literacy Pro'}

Today, Scholastic is a forerunner in educational publications providing schools and families with both top-quality print and digital learning programs. The company provides reading material to nearly 50,000 schools and libraries and has distributors in more than 20 countries across the globe. They published the first of J.K Rowling's series of Harry Potter which was a runaway fame. In addition, they have also been publishing the Kids and Family Reading report from 2006 which is fueled by their own literacy based research. The report provides key insights into the influences that affect children's reading habits, frequency and attitudes. At its core, Scholastic has always been a company driven by the commitment to help children read. Today, they are harnessing the power of adaptive technology like never before to help students improve their reading skills. 'Literacy Pro' in particular aims to connect children's independent reading to the schools' 
Literacy goals.

'Literacy Pro' facilitates ongoing assessments of reading comprehension that provide a system to track students' reading skills, monitor their progress, allow for appropriate intervention and help them to attain realistic goals. The program matches readers to leveled texts and provides them with personalized reading material to improve their Lexile scores. The program boasts of a computer-adaptive reading assessment that identifies student reading levels, recorded in Lexile measure, strongly supported by a technology-based program that promotes independent reading among students. It is recommended that students enrolled on the reading program take 3 or 4 well-spaced out tests in a school year to give students sufficient time for progress and teachers sufficient data for appropriate intervention.

A 'Literacy Pro' test consists of passages followed by questions that measure the reading ability of students by focusing on reading skills like identifying details, comparing details, drawing conclusions and making inferences. Each test question is presented in the form of a statement with four choices. The 'Literacy Pro' test uses a computer algorithm that utilizes a statistical procedure that estimates each student's ability to comprehend texts and represents it as a Lexile score. Prior information about each student's ability to read is used to control the selection of questions and the calculation of the Lexile score. 'Literacy Pro' also makes results and a variety of reports available to educators to make data-driven decision regarding student progress and attainment in reading.

\subsection{Research Hypotheses}

A focus on identifying students in need of support and providing targeted, data driven intervention, such as Response to Intervention (RtI), provides a systematic framework designed to change the trajectory of reading outcomes for struggling readers at all levels (Johnson, Mellard, Fuchs, \& McKnight, 2006). The foundation of a successful implementation of RtI for ameliorating and addressing reading difficulties is the accurate and timely identification of students with or at-risk for reading difficulties so that additional instruction/intervention can be provided (Glover \& Albers, 2007). From the measurement perspective, effective screening tools demonstrate high levels of sensitivity in accurately identifying those students who will actually encounter difficulties, as well as high level of specificity in the accurate identification of those who are not likely to demonstrate reading difficulties (Zhou, Obuchowski, \& McClish, 2002). Thus, the goal is to maximize Classification Accuracy (CA), a summative measure of overall proportion of students who were correctly identified as 'at risk' or 'not-at risk' on a screening measure (Kent, Wanzek, \& Yun, 2019). Hence, the first two hypotheses,

H01: The Classification Accuracy (CA) of the online reading program 'Literacy Pro' does not demonstrate significantly a high level of 'sensitivity' in correctly identifying those students who will actually encounter reading difficulties.

H02: The Classification Accuracy (CA) of the online reading program 'Literacy Pro' does not demonstrate significantly a high level of 'specificity' in the accurate identification of those students who are not likely to demonstrate reading difficulties.

In this study the multicomponent intervention to improve the reading comprehension skills of the students will target word order, reading fluency, and vocabulary. Task that focus on these exercises will be administered to all students, regardless of the pre-test skill performance. It is hypothesized that the effects of experimental intervention on reading comprehension would be more for students with lower pre-test performance score when compared to students with higher pre-test performance score. Here, the post-test and pre-test Lexile scores are compared and also the impact on reading skills could be measured from the benchmark examination scores of PISA, PIRLS, TIMSS and ASSET. Hence, the third hypothesis,

H03: The multicomponent intervention for improving the reading comprehension skills of students could not make significant improvement in their reading comprehension skill.

The main outcome of the literature review is that students need to learn to use a variety of effective reading strategies to comprehend foreign language texts and that higher-proficiency students can use them 
most effectively. Most of these studies establish a close relationship between language proficiency, attitude to reading and the employment of reading strategies in the samples investigated (Habók \& Magyar, 2019; Norouzian \& Mehdizadeh, 2013). In the study of Norouzian and Mehdizadeh (2013), they classified strategies into three: pre-reading, while-reading, and post-reading. The same structure was used in this study to measure the reading strategies used by the students while improving the reading literacy through the online literacy program 'Literacy Pro'. Hence, the next three hypotheses,

H04: The online reading program 'Literacy Pro' is not significantly effective in developing a 'prereading strategy' for improving the reading comprehension skill of the students.

H05: The online reading program 'Literacy Pro' is not significantly effective in developing a 'while-reading' strategy for improving the reading comprehension skill of the students.

H06: The online reading program 'Literacy Pro' is not significantly effective in developing a 'postreading strategy' for improving the reading comprehension skill of the students.

The teachers are the mediators between the online literacy program and the students in their online training of the 'Literacy Pro'. The teachers' role is to promote a learning environment that allows students to work on their strategies, train them to identify these strategies and assist their autonomy (Oxford, 1990). Hence, the hypothesis,

H07: The training provided by the teachers to assist the students to improve reading skills through the online reading program 'Literacy Pro' is not significantly effective in implementing the reading strategies and therefore could not enhance the reading comprehension skill of the students.

The ultimate impact of adopting suitable reading strategies by the students will lead to an improvement in their reading skill and the reading comprehension. Hence, the last hypothesis,

H08: The Reading strategies adopted by the students do not have significant impact on improving the reading skills or reading comprehension.

\subsection{Proposed Conceptual Framework}

The basic constructs of the study are the 1) classification accuracy in the online reading program for classifying the students into two groups, namely, at risk, and not-at risk, and 2) the efficacy of the online reading material provided by 'Literacy Pro' for improving English Reading skills and Reading comprehension. Through repeated reading practice on the online reading program, it is expected that students will adapt certain reading strategies for improving their reading skills and this has become another construct to be tested in the study.

Based on Lexile scores secured in the pre-test, the students may be categorised into two groups - 'at risk' and 'not at risk'. Any student whose Lexile score falls in the range of the below basic scores with respect to his/her Grade expected Lexile score, would be identified as 'at risk'.. Such students will receive intervention that results from informed instructional decisions made by teachers as well as through instruction, practice and independent targeted reading through the online reading program, Literacy Pro.

The Lexile level is impacted by two strong factors that determine the difficulty level of a text and in turn influence comprehension skills: word frequency (semantics) and sentence length (syntax). Lexile text measures range from below 0L to above 1600L. A Beginning Reader code (BR) is assigned to texts that are below 0L. Thus the Lexile scale may be compared to a thermometer with measures below zero marking a decrease in text difficulty level and measures above zero marking challenge. The lexile framework is designed to match reader's comprehending ability with texts that pose the appropriate challenge. Thus, the success of this model rests on the perfect match of the reader and the text. It is suggested that the desired growth and improvement in reading is expected when texts are matched to students within the range of 50L above and 100L below the students' Lexile measure. Besides, researchers like Anderson, Wilson, and Fielding (1988) surmise that students who read independently have an advantage over their peers who do not and thus outperform them.

The study will be testing the eight hypotheses H01 to H08 on the premise that the online reading 
literacy program, 'Literacy Pro' administered to the students has an effect in improving

their reading skills and reading comprehension, which would be evident from their Lexile scores obtained in a post intervention assessment and other international benchmark examinations such as PISA, PIRLS, TIMSS and ASSET. Further, the effectiveness of the online program will be evaluated on the basis of Classification Accuracy (CA) of the students at the beginning of the year in a dichotomous group- at risk (students with a low pre-test Lexile score) and not-at risk (students with a high pre-test Lexile score). The scores obtained by the students after undergoing the 'Literacy Pro' intervention (post-test Lexile score) and the scores of international benchmark examinations will be used to measure the impact of the online reading literacy program. Moreover, the students' change in their reading habit through this special training will be evaluated by the strategies adopted by the students for reading comprehension at pre-reading, while-reading, and postreading stages. These strategies would be cross checked by the teachers' recommendation of the same strategies to the students and their effectiveness in the actual practice by the students. Thus, the online reading literacy program 'Literacy Pro' would be an effective intervention tool if the program has an inbuilt feature of right classification of students as 'at risk' and 'not-at risk groups', and also if the strategies for improving reading skills (which are universally followed) are effectively adapted by the students. The diagrammatic representation of the above relationship of the different variables is given in Figure 1.

\subsection{Research Instrument}

A survey will be conducted through a validated research instrument of the previous study of Norouzian and Mehdizadeh (2013) which comprised of 4 parts- 1. General Reading Behavior (2 items), 2. Pre-Reading (7 items), While-Reading (15 items), and Post-Reading ( 8 items). In this study the first part of the questionnaire is not included. Hence, there are 30 items in total for the 3 variables under this study. The response from the students shall be received in a 5-point Likert scale which are worded as 'Never or almost Never used' (1), Generally not used (2), Sometimes used (3), Usually used (4), and Always or almost used (5). The same instrument shall be used among the teachers to record the recommendations of the teachers regarding Reading strategies. Hence, the 5-point Likert scale shall be - Never or almost never recommended (1), Generally not recommended (2), Sometimes recommended (3), Usually recommended (4), and always or almost recommended (5). The items are listed in Table1.

\subsection{Proposed Data Analysis}

The study would be quantitative and analytical based on the data collected from a real time experience of the participants in the survey. Bogdan and Biklen (1998) have aptly defined data analysis as the process of meticulously searching and organizing material that one gathers for study and subsequently sharing with others what one has observed, learned and discovered. A variety of modern analysis tools will be used for the data analysis. The diagnostic accuracy of the online reading program 'Literacy Pro' is to be validated before we look into the merit of the program in improving the reading skill/comprehension skill of the students. The foundation of the successful implementation of the program is the accurate and timely identification of the students 'at-risk' of reading difficulties so that additional instructions or interventions can be provided. As designed by the program, the students would be classified into two classes - 'At Risk', and 'Not-at Risk' based on the initial Lexile score of each student before the online program is administered to the students. From the measurement perspective, effective screening tools demonstrated high levels of sensitivity in correctly identifying those students who will actually encounter reading difficulties, as well as high levels of specificity in the accurate identification of those students who are not likely to demonstrate reading difficulties (Zhou et al., 2002). Sensitivity and Specificity are complementary and used to evaluate and compare different assessments on the same criterion. Ideally a test would have $100 \%$ sensitivity and $100 \%$ specificity, but in practice it is not possible due to measurement error and the complexity of the constructs used for measurement. Ultimately, the goal is to maximize the Classification Accuracy, a summative measure 
of the overall proportion of students who were correctly identified as 'at-risk' or 'not at-risk' on a screening measure. Although consensus has not been reached on optimum levels of sensitivity, acceptable sensitivity values noted in the literature, ranges from 0.70 to 0.90 and specificity levels of at least 0.70 for screening measures (Catts, Petscher, Schatschneider, Sittner Bridges, \& Mendoza, 2009; Compton, Fuchs, Fuchs, \& Bryant, 2006; Jenkins, Hudson, \& Johnson, 2007; Kilgus, Methe, Maggin, \& Tomasula, 2014). Initial analysis of the data will be conducted using logistic regression to investigate the screening measure (Lexile score) as an individual predictor of student performance (pass - fail) on their respective benchmark examination score. This analysis will provide the sensitivity and specificity analysis and the overall Classification Accuracy, or the percentage of the total sample correctly identified, for each of the potential screening measures.

Effective reading strategy use helps students self-direct and control their own learning process inside and outside the classrooms. To promote opportunities for a self-directed learning process, researchers suggest that teachers raise students' awareness of language learning strategies. It has been recognized that less successful learners do not progress in their tasks as more successful learners do, due to the lack of strategy use and the awareness of such strategies by the former. The mean usage of strategies will be computed from the survey data of students and same will be classified as Low (mean score 1 to 2.4), Medium (mean score 2.41 to 3.4) and High (mean score 3.41 to 5). Then, one sample t-test shall be used to prove or disprove the hypotheses.

The reading strategies survey scores of students will be compared with that of the teachers' survey scores to analyze the match between strategies adopted by students and strategies recommended by the teachers. The 'positive' and 'negative' appropriation of strategies by students will be recognized from matching scores of students and the teachers. A 'positive use' means the students used only the strategies recommended by the teachers, while 'negative use' indicates that students did not make use of the strategies recommended by the teachers. Negativity should be understood here as the mismatch between teachers' and students' reported use of strategies. A two-sample t-test shall be conducted to prove or disprove the hypothesis.

Finally, the impact of online reading program through its multi-component approach and the reading strategies adopted by students to improve their reading skills will be tested by Multiple Linear Regression (MLR) Technique. Here, the independent variables are multi-components used in the online program and the reading strategies adopted by the students and the dependent variable (outcome) is the Improvement in the students' scores for the benchmark examinations - PISA, PIRLS, TIMSS, and ASSET.

\section{References}

Al-Shehri, S., \& Gitsaki, C. (2010). Online reading: A preliminary study of the impact of integrated and split-attention formats on 12 students' cognitive load. ReCALL, 22(3), 356-375. doi:10.1017/S0958344010000212

Anderson, R. C., Wilson, P. T., \& Fielding, L. G. (1988). Growth in Reading and How Children Spend Their Time Outside of School. Reading Research Quarterly, 23(3), 285-303. Retrieved from http://www.jstor.org/stable/748043

Armstrong, S. L., \& Newman, M. (2011). Teaching Textual Conversations: Intertextuality in the College Reading Classroom. Journal of College Reading and Learning, 41(2), 6-21. doi:10.1080/10790195.2011.10850339

Auer, N. (2014, 01/01). Reading on tablets: Students' awareness and use of foreign language reading strategies. Paper presented at the Proceedings of the European Conference on e-Learning, ECEL, Copenhagen, Denmark. Retrieved from https://www.researchgate.net/publication/287185223_Reading_on_tablets_Students'_awareness_and_use_of_foreign_languag e_reading_strategies

Bernhardt, E. B. (1983). Testing Foreign Language Reading Comprehension: The Immediate Recall Protocol. Die Unterrichtspraxis / Teaching German, 16(1), 27-33. doi:10.2307/3530598

Biancarosa, G., \& Snow, C. E. (2004). Reading Next: A Vision for Action and Research in Middle and High School Literacy (Second Edition), 49. Retrieved from https://www.carnegie.org/media/filer_public/b7/5f/b75fba81-16cb-422d-ab59-373a6... Retrieved from https://www.carnegie.org/media/filer_public/b7/5f/b75fba81-16cb-422d-ab59-373a6...

Blanchard, J., McLain, J., \& Bartshe, P. (2004). The Web and Reading Instruction. Computers in the Schools, 21(3-4), 5-14. doi:10.1300/J025v21n03_02

Bogdan, R., \& Biklen, S. K. (1998). Qualitative Research for Education: An introduction to theories and methods. Boston:: Allyn and Bacon, Inc. 
Calhoon, M. B. (2005). Effects of a peer-mediated phonological skill and reading comprehension program on reading skill acquisition for middle school students with reading disabilities. Journal of Learning Disabilities, 38(5), $424-433$. doi:10.1177/00222194050380050501

Carney, R. (2010). Using Web-Based Instruction to Teach Music Theory in the Piano Studio: Defining, Designing, and Implementing an Integrative Approach. Retrieved from https://www.researchgate.net/publication/234720493_Using_WebBased_Instruction_to_Teach_Music_Theory_in_the_Piano_Studio_Defining_Designing_and_Implementing_an_Integrative_ Approach

Catts, H. W., Petscher, Y., Schatschneider, C., Sittner Bridges, M., \& Mendoza, K. (2009). Floor effects associated with universal screening and their impact on the early identification of reading disabilities. Journal of Learning Disabilities, 42(2), 163-176. doi:10.1177/0022219408326219

Chun-Min, W., \& Thomas, C. R. (2007). The Meaning of Culture in Online Education: Implications for Teaching, Learning and Desgin. In E. Andrea (Ed.), Globalized E-Learning Cultural Challenges (pp. 1-17). Hershey, PA, USA: IGI Global.

Coiro, J. (2012). The New Literacies of Online Reading Comprehension: Future Directions. The Educational Forum, 76(4), $412-417$. doi:10.1080/00131725.2012.708620

Cole, J. M., \& Hilliard, V. R. (2006). The Effects Of Web-Based Reading Curriculum On Children's Reading Performance And Motivation. J. Educational Computing Research, 34(4), 353-380. doi:10.2190/H43W-1N3U-027J-07V5

Collin, R. (2014). A Bernsteinian Analysis of Content Area Literacy. Journal of Literacy Research, 46(3), 306-329. doi:10.1177/1086296X14552178

Compton, D., Fuchs, D., Fuchs, L., \& Bryant, J. (2006). Selecting At-Risk Readers in First Grade for Early Intervention: A Two-Year Longitudinal Study of Decision Rules and Procedures. Journal of Educational Psychology, 98(2), 394-409. doi:10.1037/00220663.98.2.394

Cortazzi, M., \& Jin, L. (2008). English teaching and learning in China. Language Teaching, 29(2), 61-80. doi:10.1017/S0261444800008351

Cziko, G. (2006). Language Competence and Reading Strategies: A Comparison of First-and Second-Language Oral Reading Errors. Language Learning, 30(1), 101-114. doi:10.1111/j.1467-1770.1980.tb00153.x

Dagostino, L., \& Carifio, J. (1994). Evaluative Reading and Literacy a Cognitive View. Boston, MA: Allyn and Bacon.

Dehghanpour, E., \& Hashemian, M. (2015). Efficiency of Using a Web-Based Approach to Teach Reading Strategies to Iranian EFL Learners. English Language Teaching, 8(10), 30-41.

Eilon, B., \& Kliachko, S. (2004). Perceptions of the teacher's roles by prospective elementary school science teachers in a web-based biology course. Journal of Technology and Teacher Education, 12(3), 339-360. Retrieved from https://eric.ed.gov/?id=EJ723698

Elley, W. B. (1992). How in the World Do Students Read? Retrieved from The Hague: https://eric.ed.gov/?id=ED360613

Englert, C. S., Manalo, M., \& Zhao, Y. (2004). I Can Do It Better on the Computer: The Effects of Technology-Enabled Scaffolding on Young Writers' Composition. Journal of Special Education Technology, 19(1), 5-21. doi:10.1177/016264340401900101

Eunice Kennedy Shriver National Institute of Child Health and Human Development, N., DHHS. . (2001). Put Reading First: The Research Building Blocks for Teaching Children to Read Retrieved from Washington, DC: U.S: https://www.nichd.nih.gov/publications/product/239

Fasting, R., \& Lyster, S.-A. (2005). The effects of computer technology in assisting the development of literacy in young struggling readers and spellers. European Journal of Special Needs Education, 20(1), 21-40. doi:10.1080/0885625042000319061

Faulkner, H., \& Levy, B. (1999). Fluent and nonfluent forms of transfer in reading: Words and their message. Psychonomic bulletin \& review, 6(1), 111-116. doi:10.3758/BF03210817

Fisher, D. (2012). Teaching students to read like detectives : comprehending, analyzing, and discussing text. Bloomington, IN: Solution Tree Press.

Fishman, J. A., Ferguson, C. A., \& Dasgupta, J. (1968). Language problems of developing nations. New York: Wiley.

Foasberg, N. (2014). Student Reading Practices in Print and Electronic Media. College \& Research Libraries, 75(5), $705-723$. doi: $10.5860 / \mathrm{crl} .75 .5 .705$

Fukkink, R. G., \& de Glopper, K. (1998). Effects of Instruction in Deriving Word Meaning from Context: A Meta-Analysis. Review of educational research, 68(4), 450-469. doi:10.2307/1170735

Geske, A., \& Ozola, A. (2009). Different influence of contextual educational factors on boys' and girls' reading achievement US-China Education Review, $6(5$ (Serial No.53)). Retrieved from https://files.eric.ed.gov/fulltext/ED505734.pdf

Glover, T., \& Albers, C. (2007). Considerations for evaluating universal screening assessments. Journal of School Psychology, 45(2), 117-135. doi:10.1016/j.jsp.2006.05.005

Goodfellow, R., \& Lea, M. R. (2005). Supporting writing for assessment in online learning. Assessment \& Evaluation in Higher Education, 30(3), 261-271. doi:10.1080/02602930500063835

Grabe, W. (2009). Reading a Second Language: Moving from Theory to Practice. . New York: Cambridge University Press.

Graves, M. F., \& Watts-Taffe, S. (2008). For the Love of Words: Fostering Word Consciousness in Young Readers. The Reading Teacher, 62(3), 185-193. Retrieved from http://www.jstor.org/stable/20143930

Grubb, W. N., \& Gabriner, R. (2013). Basic skills of education in community colleges: Inside and outside of classrooms. Florence: Roultedge, Taylor and Francis Group.

Habók, A., \& Magyar, A. (2019). The effects of EFL reading comprehension and certain learning-related factors on EFL learners' reading strategy use. Cogent Education, 6(1), 1-19. doi:10.1080/2331186X.2019.1616522 
Harrison, C. (2009). On-line learning \& thinking in science: Uncovering how secondary school students learn about velocity in a Webbased environment. (Doctor of Education), Mills College. Retrieved from https://www.researchgate.net/publication/241516183_On-

line_learning_thinking_in_science_Uncovering_how_secondary_school_students_learn_about_velocity_in_a_Webbased_environment (UMI Number: 3352361)

Hart, B., \& Risley, T. R. (2003). The Early Catastrophe. The 30 Million Word Gap. American Educator, 27(1), 4-9. Retrieved from https://eric.ed.gov/?id=EJ672461

Hayes, N., \& Schrier, L. (2000). Encouraging Second Language Literacy in the Early Grades. Hispania, 83(2), $286-296$. doi: $10.2307 / 346200$

Hynd-Shanahan, C. (2013). What Does It Take? Journal of Adolescent \& Adult Literacy, 57(2), 93-98. doi:https://doi.org/10.1002/JAAL.226

Iyer, H. (2003). Web-based Instructional Technology in an Information Science Classroom. Journal of Education for Library and Information Science, 44(3/4), 296-315. Retrieved from http://www.jstor.org/stable/20764042

Jenkins, J., Hudson, R., \& Johnson, E. (2007). Screening for At-Risk Readers in a Response to Intervention Framework. School Psychology Review, 36(4), 582-599. $\quad$ Retrieved from https://www.academia.edu/27687650/Screening_for_At_Risk_Readers_in_a_Response_to_Intervention_Framework

Johnson, E., Mellard, D., Fuchs, D., \& McKnight, M. (2006). Responsiveness to Intervention (RTI): How to Do It.[RTI Manual]. Retrieved from US: https://eric.ed.gov/?id=ED496979

Jones, C. (2001). The Relationship between Writing Centers and Improvement in Writing Ability: An Assessment of the Literature. Education, 122(1), 3-13.

Kent, S. C., Wanzek, J., \& Yun, J. (2019). Screening in the Upper Elementary Grades: Identifying Fourth-Grade Students At-Risk for Failing the State Reading Assessment. Assessment for Effective Intervention, 44(3), 160-172. doi:10.1177/1534508418758371

Kern, R. G. (1989). Second Language Reading Strategy Instruction: Its Effects on Comprehension and Word Inference Ability. The Modern Language Journal, 73(2), 135-149. doi:10.1111/j.1540-4781.1989.tb02535.x

Kilgus, S. P., Methe, S. A., Maggin, D. M., \& Tomasula, J. L. (2014). Curriculum-based measurement of oral reading (R-CBM): a diagnostic test accuracy meta-analysis of evidence supporting use in universal screening. Journal of School Psychology, 52(4), 377-405. doi:10.1016/j.jsp.2014.06.002

Lamb, A., \& Johnson, L. (2010). Interactives: Dynamic Learning Environments. School Library Monthly, 26(5), 41-44. Retrieved from http://hdl.handle.net/1805/8652

Lea, M., \& Jones, S. (2011). Digital literacies in higher education: Exploring textual and technological practice. Studies in Higher Education, 36(4), 377-393. doi:10.1080/03075071003664021

Littleton, K., Wood, C., \& Chera, P. (2006). Interactions with talking books: Phonological awareness affects boys' use of talking books. J. Comp. Assisted Learning, 22(5), 382-390. doi:10.1111/j.1365-2729.2006.00183.x

Lovell, M., \& Phillips, L. (2009). Commercial Software Programs Approved for Teaching Reading and Writing in the Primary Grades: Another Sobering Reality. Journal of Research on Technology in Education, 42(2), 197-216. doi:10.1080/15391523.2009.10782547

Massey, S. (2014). Making the Case for Using Informational Text in Preschool Classrooms. Creative Education, 05(6), 396-401. doi:10.4236/ce.2014.56049

Mullis, I. V. S., Kennedy, A. M., Martin, M. O., \& Sainsbury, M. (2004). PIRLS 2006 Assessment Framework and Specifications: Progress in International Reading Literacy Study. Retrieved from https://eric.ed.gov/?id=ED484227

Nation, I. (2006). How Large a Vocabulary Is Needed for Reading and Listening? Canadian Modern Language Review-revue Canadienne Des Langues Vivantes - CAN MOD LANG REV, 63(1), 59-81. doi:10.1353/cml.2006.0049

Norouzian, R., \& Mehdizadeh, M. (2013). Reading Strategy Repertoires In EAP Contexts: Students And Teachers In Academic Reading Strategy Use. The International Journal of Language Learning and Applied Linguistics World (IJLLALW), 3(1), 1-11. Retrieved

from https://www.academia.edu/8059918/The_International_Journal_of_Language_Learning_and_Applied_Linguistics_World_IJL LALW_READING_STRATEGY_REPERTOIRES_IN_EAP_CONTEXTS_STUDENTS_AND_TEACHERS_IN_ACADEM IC_READING_STRATEGY_USE

Oxford, R. L. (1990). Language Learning Strategies: What Every Teacher Should Know (Vol. 1). New York: Newbury House.

Palmer, D. (2006). A Motivational View of Constructivist-informed Teaching. International Journal of Science Education, 27(15), 18531881. doi:10.1080/09500690500339654

Park, H.-R., \& Kim, D. (2011). Reading strategy use by English as a second language learners in online reading tasks. Computers \& Education, 57(3), 2156-2166. doi:10.1016/j.compedu.2011.05.014

Perlman, C., Weston, C., \& Gisel, E. (2010). Enabling meaningful learning through Web-based instruction with occupational therapy students. Educational Technology Research and Development, 58(2), 191-210. doi:10.1007/s11423-008-9097-2

Rashotte, C. A., \& Torgesen, J. K. (1985). Repeated Reading and Reading Fluency in Learning Disabled Children. Reading Research Quarterly, 20(2), 180-188. Retrieved from http://www.jstor.org/stable/747754

Reutzel, D. R., \& Cooter, R. B. (2004). Teaching Children to Read: Putting the Pieces Together. Fourth Edition. Columbus: OH: Merrill/Prentice- Hall Publishing Company.

Richmond, E. B. (1980). Literacy and Language Teaching in The Gambia. The Modern Language Journal, 64(4), 416-421. doi:https://doi.org/10.1111/j.1540-4781.1980.tb05214.x 
Sadik, A. (2008). Digital storytelling: a meaningful technology-integrated approach for engaged student learning. Educational Technology Research and Development, 56(4), 487-506. doi:10.1007/s11423-008-9091-8

Schmar-Dobler, E. (2003). Reading on the Internet: The Link between Literacy and Technology. Journal of Adolescent and Adult Literacy, $\quad 47(1), \quad 80-85$ from https://www.researchgate.net/publication/287009870_Reading_on_the_Internet_The_Link_between_Literacy_and_Technolog $\mathrm{y}$

Shanahan, L. E. (2006). Reading and writing multimodal texts through information and communication technologies. (Doctor of Philosophy), State University of New York at Buffalo, ProQuest Information and Learning Company, USA. Retrieved from https://search.proquest.com/docview/304937897?pq-origsite=gscholar\&fromopenview=true $(3213623)$

Shanahan, T., \& Shanahan, C. (2012). What Is Disciplinary Literacy and Why Does It Matter? Topics in Language Disorders, 32(1), 718. doi:10.1097/TLD.0b013e318244557a

Sherman, D., Kleiman, G., \& Peterson, K. (2004). Technology and Teaching Children to Read. Retrieved from https://eric.ed.gov/?id=ED485613

Smith, G. E., \& Throne, S. (2007). Differentiating instruction with technology in K-5 classrooms. Or: International Society for Technology in Education.

Smith., M. (2005). Literacy and augmentative and alternative communication Vol. xv. (pp. 268). Retrieved from https://libris.kb.se/bib/9684716 Retrieved from https://libris.kb.se/bib/9684716

Stanovich, K. E., \& Cunningham, A. E. (1992). Studying the consequences of literacy within a literate society: The cognitive correlates of print exposure. Memory \& Cognition, 20(1), 51-68. doi:10.3758/BF03208254

Stewart-Dore, N. (2013). Coda: From Content Area Reading to Disciplinary Literacy. Literacy Learning: The Middle Years, 21(1), 48-50. Retrieved from https://search.informit.com.au/documentSummary;dn=107253938577075;res=IELHSS;type=pdf

Vasquez, K. (2009). Learning styles as self-fulfilling prophecies Getting culture: incorporating diversity across the curriculum (pp. 5363). Virginia, US: Stylus Publishing.

White, S. A. (2004). Reading strategies training in a Japanese university English as a foreign language setting. (Doctor of Philosophy), University of Kansas, ProQuest Dissertations Publishing. Retrieved from https://search.proquest.com/docview/305170514?pqorigsite $=$ gscholar \&fromopenview $=$ true $(3185246)$

Wolf, D. (2011). A Comparison of Assessment Tasks Used to Measure FL Reading Comprehension. The Modern Language Journal, 77(4), 473-489. doi:10.1111/j.1540-4781.1993.tb01995.x

Zhang, D. (2012). Vocabulary and Grammar Knowledge in Second Language Reading Comprehension: A Structural Equation Modeling Study. The Modern Language Journal, 96(4), 558-575. doi:10.2307/23361716

Zhou, X. H., Obuchowski, N., \& McClish, D. (2002). Statistical Methods in Diagnostic Medicine, Second Edition.

Zwaan, R. A., \& Rapp, D. N. (2006). Chapter 18 - Discourse Comprehension. In M. J. Traxler \& M. A. Gernsbacher (Eds.), Handbook of Psycholinguistics (Second Edition) (pp. 725-764). London: Academic Press. 